\title{
Maximizing Plating Density and Efficiency for a Negative Deposition \\ Reaction in a Flow Battery
}

Krista L. Hawthorne ${ }^{\mathrm{a}, *}$, Jesse S. Wainright ${ }^{\text {a }}$, Robert F. Savinell ${ }^{\text {a }}$

${ }^{a}$ Department of Chemical Engineering, Case Western Reserve University, 10900 Euclid Ave, Cleveland, Ohio 44106

*corresponding author

Phone: (505) 385-7170

Fax: (216) 368-3016

Email: KristaLHawthorne@gmail.com 


\begin{abstract}
Flow batteries utilizing a plating reaction as the negative reaction are limited in energy capacity by the available void area in the cell stack. Large scale energy storage applications necessitate maximizing the plating density within the flow battery. Six porous negative electrode configurations using conductive and non-conductive materials are considered for use in a hybrid flow battery. Plating results using a $\mathrm{Cu}-\mathrm{Fe}$ sulfate chemistry demonstrated a plating density in a carbon felt electrode (145 $\mathrm{mAh} \mathrm{cm}^{-2}$ at $40 \mathrm{~mA} \mathrm{~cm}^{-2}$ ). Two layered electrode configurations were able to achieve $150 \mathrm{mAh} \mathrm{cm}^{-2}$ of plating density: carbon felt with non-conductive felt, and carbon felt-Daramic-carbon felt. Both electrode designs were tested with the all-iron chemistry using shallow charge/discharge cycles. The carbon felt with non-conducting felt electrode configuration maintained a voltaic efficiency of $81 \%$ over six cycles.
\end{abstract}




\section{Introduction}

Use of renewable energy sources on the power grid is challenging as most renewable sources provide intermittent energy, and the production must be tailored to match the real time variation in energy demand [1]. However, grid-scale energy storage technology can be used in tandem with intermittent energy sources to help balance energy supply and demand. Flow batteries are a promising approach for large scale energy storage since the external storage of electrolyte eases scaling of the batteries to the grid scale [2, 3]. Redox flow batteries (RFBs) employ a redox chemistry at both electrodes, such as the all-vanadium [2] and the iron-chrome $[4,5]$ systems. In addition, there are several flow batteries operated in a hybrid configuration. Hybrid flow batteries, such as the all-iron system [6] and zinc-halogen systems [7, 8] involve plating/stripping of metal deposits at the negative electrode. This limits the amount of energy that can be stored and the energy capacity is directly related to the amount of metal that can be plated within the stack [7].

One of the most common examples of a hybrid flow battery negative electrode involves the $\mathrm{Zn}^{2+} / \mathrm{Zn}^{0}$ couple $[7,9,10]$, usually with a bromine or chlorine positive electrode, though other redox couples such as cerium [11] have been proposed. The simplest negative electrode design for a zinc flow battery is a flat plate electrode structure, where the zinc plates and strips on a second metal substrate [10-12]. The boundary layer on a flat plate in laminar flow is relatively thick (about $85 \mu \mathrm{m}$ at $\left.2.5 \mathrm{~cm} \mathrm{~s}^{-1}\right)$, meaning the limiting current density is low $\left(\approx 65 \mathrm{~mA} \mathrm{~cm}{ }^{-2}\right.$ for $1 \mathrm{M}$ reactant concentration and $\mathrm{n}=1$ ). Consequently, current densities reported in the literature on flat plate electrode designs are often between $15 \mathrm{~mA} \mathrm{~cm}^{-2}$ [10] and $45 \mathrm{~mA} \mathrm{~cm}^{-2}$ [8]. Cheng, et. Al. [12] compared a flat plate with a three dimensional nickel foam electrode for use in a $\mathrm{Zn}-\mathrm{Ni}$ 
flow battery, and were able to operate at $80 \mathrm{~mA} \mathrm{~cm}^{-2}$ with a round trip energy efficiency of $80 \%$. The all-iron flow battery chemistry involves iron plating/stripping on the negative electrode and the ferric/ferrous couple for the positive electrode. In the literature, an all-iron flow battery was reported having a flat plate negative electrode operating at $60 \mathrm{~mA} \mathrm{~cm}^{-2}$ and a current efficiency of $90 \%$, with the main efficiency loss due to competing hydrogen evolution [6]. More recently, a soluble lead-acid chemistry (using lead (II) methanesulfonate as the dissolved species) has been considered for use in a flow battery configuration, with $\mathrm{Pb}(0) / \mathrm{Pb}(\mathrm{II})$ as the negative electrode and $\mathrm{Pb}(\mathrm{II}) / \mathrm{PbO}_{2}$ as the positive electrode [13]. Both reactions in this case involve deposition of solid materials in the battery stack from a liquid electrolyte. Soluble lead-acid battery operation has been reported at currents between 10 and $60 \mathrm{~mA} \mathrm{~cm}^{-2}$ using a flat Ni plate electrode, and demonstrated charge/discharge behavior similar to a traditional lead-acid battery $[14,15]$. Cell performance at currents between 10 and $100 \mathrm{~mA} \mathrm{~cm}^{-2}$, using a reticulated vitreous carbon electrode structure, has also been reported for the soluble lead chemistry with round trip energy efficiencies of up to $70 \%$ [13].

The cost of any flow battery is directly proportional to the membrane area of the cell, and high power densities will reduce the battery capital cost. Therefore the limiting current density of a flow battery needs to be high to accommodate high current density operation. Hybrid flow batteries are also limited by the amount of metal that can be deposited into the electrode structure, thus controlling the amount of discharge time at power available. For example, an economic current density might be $100 \mathrm{~mA} \mathrm{~cm}{ }^{-2}$, and a typical plating density might be $200 \mathrm{mAh}$ $\mathrm{cm}^{-2}$, thus resulting in a two hour discharge. 
Employing a three dimensional porous electrode instead of a flat plate will increase active surface area and apparent mass transport rates, thus increasing the limiting current density. In addition, three-dimensional electrodes might also increase the effective plating density that can be obtained. In this paper we examine six different three-dimensional structures for their performance as a negative electrode substrate for a metal deposition and dissolution reaction. Combinations of conductive and non-conductive porous materials were examined for their energy storage capacity. For this study we used copper plating from sulfate electrolytes to examine the effectiveness of the electrode structures. This reaction is kinetically fast and about $370 \mathrm{mV}$ positive of hydrogen evolution, therefore it any avoids complications from hydrogen evolution as a side reaction. Two of the better performing electrodes were also incorporated into an all-iron flow battery to evaluate their efficacy in this hybrid flow battery system.

\section{Experimental}

\subsection{Materials and Reagents}

All chemicals were of reagent grade. $\mathrm{H}_{2} \mathrm{SO}_{4}, \mathrm{HNO}_{3}, \mathrm{CuSO}_{4}, \mathrm{Na}_{2} \mathrm{SO}_{4}$, and methanol were obtained from Fisher Scientific (Waltham, MA). $\mathrm{FeSO}_{4}$ was obtained from Acros Organics (Geel, Belgium). $\mathrm{FeCl}_{2}, \mathrm{FeCl}_{3}, \mathrm{NH}_{4} \mathrm{Cl}$, and glycerol were obtained from Alfa Aesar (Ward Hill, MA). All electrolytes were made with deionized water (Millipore MilliQ-UV Plus).

For the flow battery experiments, carbon felt was obtained from GrafTech (Cleveland, $\mathrm{OH}$ ) in 4 $\mathrm{mm}$ and $2 \mathrm{~mm}$ thicknesses. Carbon cloth (AvCarb Grade - 1071HCB, $380 \mu \mathrm{m}$ thickness) and carbon paper (Spectracarb 2050-L, $260 \mu \mathrm{m}$ thick) were obtained from the Fuel Cell Store 
(College Station, TX). Carbon cloth and carbon felt materials were all pre-treated with nitric acid [16] to improve wettability. The felt or cloth was soaked in $1 \mathrm{M}^{\mathrm{HNO}} 3$ for one hour and then rinsed with deionized water until the $\mathrm{pH}$ of the rinse water reached 6 . The non-conducting (nonelectrically conductive) felt used was a polyester filter felt with a $5 \mu \mathrm{m}$ pore diameter and $2 \mathrm{~mm}$ thickness (\#6376T31, McMaster-Carr, Aurora, OH). A $220 \mu$ m thick Daramic (175 SLI Flatsheet Membrane) separator material was obtained from Daramic (Charlotte, NC). Nafion 117 (Proton Power, Lenoir City, TN) was also used as a separator. Conductive carbon ink (Electrodag 421 SS) was obtained from Acheson (owned by Henkel, Dusseldorf, Germany). Unless otherwise stated, all experiments with flow battery hardware used graphite flow fields $\left(38.5 \mathrm{~cm}^{2}\right.$ active area) obtained from TDM Inc. (Ashtabula, $\mathrm{OH})$.

\subsection{Bonding Procedure}

Some of the carbon felts and non-conducting felts were bonded to the graphite flow fields used in the flow batteries to improve the interfacial electrical conductivity. Bonding was done by applying a thin layer of conductive carbon ink to the flow field, gently pressing the desired felt or cloth into the wet ink, and then curing at $70{ }^{\circ} \mathrm{C}$ for 30 minutes in air.

\subsection{Rotating Cylinder Electrode}

Rotating cylinder experiments were performed using a copper rod $(99.9 \%$ pure, 5 mm diameter, Alfa Aesar, Ward Hill, MA) masked to a $1 \mathrm{~cm}^{2}$ active area. Any surface oxides were removed from the copper surface by soaking the rod in $1 \mathrm{M} \mathrm{H}_{2} \mathrm{SO}_{4}$ overnight before use. Bonded nonconducting felt rotating rod experiments were performed by bonding a piece of the nonconducting felt over the active area (Figure 1). The non-conducting felt was cut to $150 \%$ of the 
active area, overhanging the exposed copper by $1.5 \mathrm{~mm}$ on each side to prevent preferential plating due to any exposed conductive ink. Experiments were performed in $0.2 \mathrm{M} \mathrm{FeCl}_{2}$ and $1 \mathrm{M}$ $\mathrm{NH}_{4} \mathrm{Cl}$, with an iron rod counter electrode $(99.9 \%$ pure, $5 \mathrm{~mm}$ diameter, Alfa Aesar, Ward Hill, $\mathrm{MA}$ ) and a $\mathrm{Ag} / \mathrm{AgCl}$ reference electrode (BASi, West Lafayette, IN). The cell was purged with nitrogen for the duration of the experiments, and the electrode was rotated at $1500 \mathrm{rpm}$ for both cyclic voltammetry and constant plating experiments. Cyclic voltammetry was performed at 50 $\mathrm{mV} \mathrm{s}^{-1}$ on a fresh electrode, after deposition of $20 \mathrm{mAh} \mathrm{cm}^{-2}$ of iron, and after deposition of 480 $\mathrm{mAh} \mathrm{cm}$ of iron. Iron was deposited at $-20 \mathrm{~mA} \mathrm{~cm}^{-2}$ to obtain the targeted plating density. All electrochemistry was performed on a Solartron Analytical Modulab 2101A Potentiostat (Farnborough, Hampshire, United Kingdom).

\subsection{Symmetric Cells}

Four $38.5 \mathrm{~cm}^{2}$ flow battery cells were run as symmetric $\mathrm{Fe}^{2+/ 3+}$ redox cells. A single reservoir of electrolyte was used, consisting of $0.2 \mathrm{M} \mathrm{FeCl}_{2}, 0.2 \mathrm{M} \mathrm{FeCl}_{3}$, and $1 \mathrm{M} \mathrm{NaCl}$. The electrolyte was controlled at $50 \mathrm{~mL} \mathrm{~min}^{-1}$ in series through the anode (working electrode) and cathode (counter electrode) of the cell. One electrode oxidizes $\mathrm{Fe}^{2+}$ to $\mathrm{Fe}^{3+}$, the other electrode reduces $\mathrm{Fe}^{3+}$ to $\mathrm{Fe}^{2+}$. Since a single reservoir is used, there is no change in the concentration of either species. Flow cell hardware consisting of CPVC end plates, graphite flow fields, and a Daramic separator with a $38.5 \mathrm{~cm}^{2}$ area was used in a flow-through configuration [17]. The flow fields included an inlet and outlet header $100 \mu \mathrm{m}$ deep. Four electrode structures were tested in the symmetric cells: A, bonded carbon felt; B, non-bonded carbon felt; C, bonded non-conducting felt; and D, nonbonded non-conducting felt. The electrode structure on each side of the battery was the same. 
Electrochemical Impedance Spectroscopy (EIS) was performed on each cell around the open circuit potential with a $\pm 10 \mathrm{mV}$ perturbation, from $20,000 \mathrm{~Hz}$ to $0.2 \mathrm{~Hz}$.

\subsection{Flow-by Flow Battery Experiments}

An initial flow battery experiment was performed in $5 \mathrm{~cm}^{2}$ serpentine hardware (Fuel Cell Technologies, Albuquerque, NM) [7]. Both the positive and negative electrodes consisted of two pieces of carbon paper, and the cell had a Nafion 117 membrane. The flow rate was controlled at $50 \mathrm{~mL} \mathrm{~min}^{-1}$. The same electrolyte composition was used on both the positive and negative side of the battery, consisting of $1 \mathrm{M} \mathrm{FeSO}_{4}, 1 \mathrm{M} \mathrm{CuSO}_{4}$, and $1 \mathrm{M} \mathrm{Na}_{2} \mathrm{SO}_{4}$, with the $\mathrm{pH}$ adjusted to 1 by addition of $\mathrm{H}_{2} \mathrm{SO}_{4}$. The cell was charged at $40 \mathrm{~mA} \mathrm{~cm}$ for $110 \mathrm{~min}$.

\subsection{Cu Sulfate Flow Battery Experiments}

$\mathrm{Cu}$-Fe sulfate flow battery experiments were performed in the $38.5 \mathrm{~cm}^{2}$ flow-through cell hardware with a Nafion 117 membrane. All experiments were performed with electrolyte flow rates of $50 \mathrm{~mL} \mathrm{~min}^{-1}$. The $\mathrm{Cu}-\mathrm{Fe}$ sulfate positive electrolyte contained $500 \mathrm{~mL}$ of $1 \mathrm{M} \mathrm{FeSO}_{4}$ and $1 \mathrm{M} \mathrm{Na}_{2} \mathrm{SO}_{4}$, adjusted to a $\mathrm{pH}$ of 1 with $\mathrm{H}_{2} \mathrm{SO}_{4}$. For the positive electrode, a piece of carbon felt was treated using nitric acid as previously stated, and bonded to the graphite flow field. Before use, the carbon felt was wetted using methanol for 10 minutes, which was then exchanged with deionized water. The negative electrolyte consisted of $250 \mathrm{~mL}$ of $1 \mathrm{M} \mathrm{CuSO}_{4}$ and $1 \mathrm{M} \mathrm{Na}_{2} \mathrm{SO}_{4}$, adjusted to a pH of 1 with $\mathrm{H}_{2} \mathrm{SO}_{4}$. Six negative electrode configurations were tested, as outlined in Figure 2. Electrodes with a single piece of carbon felt used the $4 \mathrm{~mm}$ thick felt. Electrodes with multiple layers containing carbon felt used the $2 \mathrm{~mm}$ thick felt. All carbon felts and cloths used in the negative electrodes were treated with nitric acid and wetted with methanol, as with 
the positive electrode. Bonding was performed using the same method as described for the positive electrode (both for carbon felts/cloths and the non-conducting felts). Layers in the negative electrodes were not bonded to each other, rather the battery relied on compression (to $80 \%$ of the initial electrode thickness) to maintain contact.

Unless otherwise noted, all batteries were charged at $40 \mathrm{~mA} \mathrm{~cm}{ }^{-2}$ for 3.75 hours, for a total

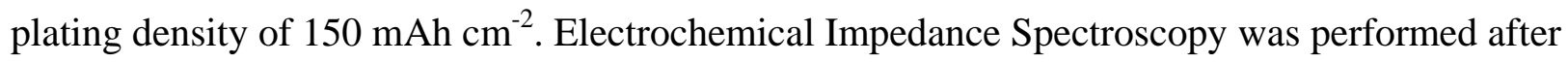
the initial charge at the open circuit potential with a $\pm 10 \mathrm{mV}$ perturbation, from $20,000 \mathrm{~Hz}$ to 0.2 $\mathrm{Hz}$.

\subsection{All-Iron Flow Battery Experiments}

All-iron flow battery experiments were performed in the $38.5 \mathrm{~cm}^{2}$ flow-through cell hardware with a Nafion 117 membrane. The flow fields consisted of an inlet and outlet header $100 \mu \mathrm{m}$ deep, and the electrodes were in a flow-through configuration [17]. All experiments were performed at $50 \mathrm{~mL} \mathrm{~min}{ }^{-1}$. Additionally, the all-Fe batteries were run at $60{ }^{\circ} \mathrm{C}$ instead of room temperature. Electrolyte for both the positive and negative electrodes consisted of $1.5 \mathrm{M} \mathrm{FeCl}_{2}$, 1.5 $\mathrm{M} \mathrm{NH}_{4} \mathrm{Cl}$, and $2.5 \mathrm{M}$ glycerol used as a complexing agent for maintaining Fe(III) solubility $[18,19]$. In the positive electrolyte, $0.5 \mathrm{M} \mathrm{FeCl}_{3}$ was added for stability of the ferric/ferrous redox couple potential. The positive electrode was prepared in the same manner as for the $\mathrm{Cu}-\mathrm{Fe}$ sulfate batteries, by bonding a piece of nitric acid treated carbon felt to the flow field, wetting with methanol for 10 minutes, then exchanging the methanol with deionized water. Only two negative electrode configurations were tested in the all-Fe batteries, designated $\mathrm{E}$ and $\mathrm{F}$ in Figure 
All batteries were charged at $40 \mathrm{~mA} \mathrm{~cm}{ }^{-2}$ for 3.75 hours, for a total plating density of $150 \mathrm{mAh}$ $\mathrm{cm}^{-2}$. Electrochemical Impedance Spectroscopy was performed after the initial charge at the open circuit potential with $\pm 10 \mathrm{mV}$ perturbations, from $20,000 \mathrm{~Hz}$ to $0.2 \mathrm{~Hz}$. Charge-discharge cycling for the all-Fe batteries were performed at $-40 \mathrm{~mA} \mathrm{~cm}{ }^{-2}$ for 30 minutes on discharge and $+40 \mathrm{~mA} \mathrm{~cm}^{-2}$ for 30 minutes on charge, with a total of 6 cycles.

\section{Results and Discussion}

\subsection{Current Distribution}

Plating density in the hybrid RFB is dependent on the current distribution within the porous electrode. Models for the current distribution in porous electrodes are well studied, with the distribution dependent on the physical structure of the electrode, the electronic and ionic conductivities of the electrode and electrolyte phases, and on the mass transfer and kinetic resistances [20-22]. In the case of a flow battery, the velocity of the electrolyte through the porous electrode minimizes the mass transfer resistances. The current distribution can then be calculated based on the Butler-Volmer equation and the ohmic resistances for both the solid and electrolyte phases, as a function of depth in the porous electrode. Figure 3 shows the one dimensional current distribution with varying electronic conductivities $\left(\sigma_{\mathrm{e}}\right)$, where a depth of 0 $\mathrm{cm}$ corresponds to the current collector and a depth of $0.5 \mathrm{~cm}$ corresponds to the electrode/membrane interface. The ionic conductivity was held constant at $0.1 \mathrm{~S} \mathrm{~cm}^{-1}$ in these calculations. The distribution where $\sigma_{\mathrm{e}}=1 \mathrm{~S} \mathrm{~cm}^{-1}$ reflects that of a typical flow battery having a carbon felt or carbon paper electrode, where the electrode conductivity is much higher than that 
of the electrolyte [23]. In this case, the majority of the current is concentrated near the membrane. For a negative electrode involving electrodeposition of a metal, the bulk of the plating will then occur near the membrane surface. As plating occurs, the porosity of the electrode decreases. Once the pores of the felt are full with metal deposit, ion transport is restricted into the porous network, resulting in a significant increase in the overpotentials and eventual failure of the battery. This is demonstrated in Figure 4 for copper deposition from a sulfate electrolyte using a serpentine flow field and carbon paper electrodes $\left(\mathrm{Fe}^{2+} / \mathrm{Fe}^{3+}\right.$ couple on the positive electrode). The battery started charging at about $0.55 \mathrm{~V}(120 \mathrm{mV}$ total overpotential), and reached $0.63 \mathrm{~V}$ (a $200 \mathrm{mV}$ overpotential) within one hour of charging at 40 $\mathrm{mA} \mathrm{cm}^{-2}$. The cell ultimately failed when the cell voltage reached $1.14 \mathrm{~V}$ (total overpotential of $710 \mathrm{mV}$ ). The total density of copper deposited was $73 \mathrm{mAh} \mathrm{cm}{ }^{-2}$, however the amount of copper deposited at reasonable overpotentials (under $200 \mathrm{mV}$ ) was closer to $20 \mathrm{mAh} \mathrm{cm}^{-2}$. When the cell was taken apart, the face of the carbon paper that was against the membrane was filled with copper (Figure 5a), while the current collector side of the paper showed very little copper deposition (Figure 5b), as expected by the current distribution predicted in Figure 4. Copper deposition was also observed along the edges of the carbon paper. As the mass transfer resistance and overpotential increased, the edges of the paper were more likely to be accessed by ions to be plated.

If the electronic conductivity is reduced in magnitude, the maximum in the current distribution can be shifted away from the membrane and towards the current collector (Figure 3). When the ratio of electronic conductivity to ionic conductivity equals unity, there is a symmetric current distribution. Significantly lowering the ratio of electronic conductivity to ionic conductivity, say 
to 0.05 , shifts the maximum in the current distribution moves towards to the current collector. In the extreme of very low ratio of electronic conductivity to ionic conductivity, the current density concentrates near the current collector much like that of a flat plate electrode. However, even in this case, the low-conducting electrode structure may provide some benefit by increasing the mass transfer rates over those of a flat plate, allowing operation at higher current densities. The low-conducting electrode structure does increases the ionic resistance in the region between the membrane and the current collector, but also serves as a membrane support.

To explore the resistive losses with conducting and non-conducting electrode materials further, symmetric cell experiments were carried out with four different electrode configurations: A, bonded carbon felt; B, non-bonded carbon felt; C, bonded non-conducting felt; and D, nonbonded non-conducting felt. Electrochemical impedance spectroscopy (EIS) measurements were performed on all configurations using a single reservoir with $\mathrm{Fe}(\mathrm{II})$ and $\mathrm{Fe}(\mathrm{III})$, flowing in series through the RFB anode and cathode (Figure 6). The charge transfer resistances for cases A and B (the carbon felts), are small, and no mass transfer resistance is observed. Bonding the felts serves to decrease the interfacial resistances and lower the high frequency resistance. For cases C and D (the non-conducting felts), the high frequency resistance is increased over cases A and B (about $5 \Omega \mathrm{cm}^{2}$ for case D versus $2.9 \Omega \mathrm{cm}^{2}$ for case B). A significant charge transfer and mass transfer resistance are observed in case D (non-bonded non-conducting felt). Though the non-conducting felt will somewhat break up the boundary layer, the active electrode area in case D is limited to the flat graphite plate. When the non-conducting felt was bonded to the current collector, the high frequency resistance decreased to $3 \Omega \mathrm{cm}^{2}$, and the charge transfer resistance also decreased. The conductive carbon ink will have a somewhat higher surface area than that of the 
flat plate current collector (the wet ink is partly forced into the pores of the non-conducting felt), most likely the reason for the decreased charge transfer resistance. The similarities in high frequency resistance values between the bonded carbon felt and the bonded non-conducting felt demonstrates that an electrode of bonded non-conducting felt will not significantly increase ohmic losses in a flow battery.

\subsection{Rotating Rod Experiments}

To further investigate the use of a non-conducting felt bonded to a current collector as an electrode for a plating reaction, a rotating rod configuration was used, as described in the experimental section. Cyclic voltammetry measurements of iron plating and stripping were recorded with the bonded non-conducting felt rod electrode rotated at $1500 \mathrm{rpm}$, and after plating $20 \mathrm{mAh} \mathrm{cm}^{-2}$ and $480 \mathrm{mAh} \mathrm{cm}^{-2}$ (Figure 7). The CVs are compared to the iron plating/stripping cyclic voltammetry on a bare copper rod $\left(1 \mathrm{~cm}^{2}\right.$ active area) within the same electrolyte. As the plating density increased, the CVs indicate that iron deposition occurs at lower overpotentials. Also, the rotating rod with the attached non-conducting felt enabled iron metal deposition at lower overpotentials as compared to plating on the bare copper rod. It is important to note that the plating densities calculated on the rotating rod do not take into account any hydrogen evolution occurring (plating density was estimated based on the applied current and plating time). The true plating density of iron plated is most likely somewhat less than the estimated values presented here. Even so, these results indicate that using a non-conducting felt bonded to the current collector as an electrode structure can lower the plating overpotential and enable a high plating density (possibly as high as $480 \mathrm{mAh} \mathrm{cm}^{-2}$ ). 


\subsection{Copper Sulfate Flow Batteries}

All six negative electrode structures shown in Figure 2 were tested in the $\mathrm{Cu}-\mathrm{Fe}$ sulfate battery. The copper negative electrode was chosen for these plating capacity studies to minimize the effects of hydrogen evolution as a competing reaction. Electrodes A and B are traditional flow through carbon felt electrodes. In electrode A, the felt is bonded to the current collector, where as in electrode $\mathrm{B}$ the felt is non-bonded. Electrode $\mathrm{C}$ is the bonded non-conducting felt. Electrodes $\mathrm{D}$ and $\mathrm{E}$ use the non-conducting felt on top of a bonded conductive electrode, either carbon cloth (D) or carbon felt (E). The porous carbon materials in electrodes D and E are used to decrease the kinetic overpotentials while the layer of non-conducting felt prevents plating directly onto the membrane. Electrode F consists of three layers: bonded carbon felt, a Daramic porous nonconducting separator, and a second layer of carbon felt. The Daramic initially isolates the layer of carbon felt bonded to the current collector from the layer of carbon felt near the membrane surface.

Each battery was charged at $40 \mathrm{~mA} \mathrm{~cm}^{-2}$ until either reaching $150 \mathrm{mAh} \mathrm{cm}^{-2}$ (220 minutes) or failing, as indicated by a sharp spike in the potential (Figure 8). A summary of the plating density achieved before failure and the cell voltage during plating for each configuration is presented in Table 1. Of the six batteries, electrodes A, B, C, and D failed before reaching the targeted plating density of $150 \mathrm{mAh} \mathrm{cm}^{-2}$. Electrodes A and B charged at the lowest overpotentials as expected. Both A and B contain only carbon felt: a layer of non-conducting felt (as in electrodes $\mathrm{C}, \mathrm{D}$, and $\mathrm{E}$ ) adds a gap of zero electronic conductivity (so the ohmic overpotential will depend entirely on the ionic conductivity) and the ohmic overpotential will increase. Electrode $\mathrm{C}$ failed at $124 \mathrm{mAh} \mathrm{cm}^{-2}$, the lowest plating density of the six electrode 
configurations. Electrode $\mathrm{C}$ corresponds to the configuration used in the rotating rod experiments, of which iron was plated to an estimated $480 \mathrm{mAh} \mathrm{cm}^{-2}$. Two explanations for the discrepancy in plating density exist. First, the rotation rate used in the rotating rod experiments provided a much higher solution velocity than what was used in the $\mathrm{Cu}-\mathrm{Fe}$ sulfate battery. The higher velocity would be expected to result in a higher limiting current density which should yield a smoother, more conformal deposit. Second, the iron plating potentials on the rotating rod are well within the boundaries of hydrogen evolution, while the copper plating potential is more positive than hydrogen evolution and will therefore have a higher current efficiency. These results suggest that use of a bonded non-conducting felt as the plating electrode structure will not provide a high plating density. Electrode $\mathrm{D}$ charged at a lower potential than electrode $\mathrm{E}(0.7 \mathrm{~V}$ versus $1.0 \mathrm{~V}$ ), but ultimately failed at $145 \mathrm{mAh} \mathrm{cm}^{-2}$. The carbon cloth in electrode $\mathrm{D}$ provides a thin layer of conductive porous media, increasing the plating density over electrode $\mathrm{C}$, however the electrode structure is still not able to provide $150 \mathrm{mAh} \mathrm{cm}^{-2}$ of plating capacity. The bonded carbon felt and non-conducting felt (E) and the bonded carbon felt-Daramic-carbon felt (F) electrodes both successfully reached the targeted $150 \mathrm{mAh} \mathrm{cm}^{-2}$ of copper deposit. The chargingtime profile for both of these electrodes showed a relatively constant potential, and there was not a rapid rise in charging potential for either electrode.

The EIS results for electrodes C, D, E, and F are reported in Figure 9, and the high frequency resistance calculated from the EIS is reported in Table 1. EIS for electrodes A and B could not be measured due to a high density of copper along the membrane, blocking ion transport in the porous network (EIS measurements were taken at the end of the initial charge). Electrode $\mathrm{C}$ has the largest high frequency resistance, but a low charging potential $\left(3.85 \Omega \mathrm{cm}^{2}\right.$ and $0.75 \mathrm{~V}$, 
respectively). As the electrode structure consists only of the non-electrically conducting felt, a large high frequency resistance is expected, and the low charging potential indicates that plating kinetics and mass transfer are not hindered. Electrode F contained the smallest thickness of nonelectrically conductive media (a single piece of Daramic), and had both the lowest high frequency resistance and lowest charging potential $\left(1.93 \Omega \mathrm{cm}^{2}\right.$ and $0.79 \mathrm{~V}$, respectively). Electrode D had a lower high frequency resistance than electrode $\mathrm{C}$ due to the layer of carbon cloth $\left(2.31 \Omega \mathrm{cm}^{2}\right.$ versus $\left.3.85 \Omega \mathrm{cm}^{2}\right)$. Electrodes D and E contained a layer of conductive media and a layer of non-conducting felt, contributing to their higher resistances and charging potentials. The mass transfer resistance in all electrode structures can be considered to be small, as indicated by the impedance spectra, due to the relatively high flow rate of electrolyte through the cell. All of the charge transfer semicircles in the EIS results are depressed, indicating a distributed ionic resistance through the electrode. As a result, the charge transfer resistance cannot be directly calculated; rather, an electrode resistance (the combined charge transfer resistance and distributed ionic resistance) can be estimated by the width of the depressed semicircle and used to compare the negative electrode structures. The EIS for electrode $\mathrm{C}$ has the largest electrode resistance, due to the absence of any conductive porous media (carbon felt or carbon cloth). This configuration would be expected to have the lowest surface area and thus the highest charge transfer resistance. The electrode resistances for electrodes D, E, and F are much closer in size, as they all contain at least one layer of conductive, high surface area media.

When cells D and E were taken apart, copper deposit was observed throughout the conductive media. In electrode E (bonded carbon felt and non-conducting felt), no copper was observed in the non-conducting felt, only throughout the carbon felt layer (Figure 10a). These results are in 
agreement with the current distribution discussed in the previous section: the majority of the current will be concentrated at the interface between the electrode and the adjacent region of purely ionically conducting material (in this case, the non-conducting felt). In electrode F, the bonded carbon felt-Daramic-carbon felt, a copper deposit was observed in both layers of carbon felt. In the bonded carbon felt layer, the copper was concentrated on the side next to the Daramic layer (Figure 10b), and in the carbon felt layer between the Daramic and membrane, copper was concentrated on the side of the felt facing the membrane (Figure 10c). The plating distribution in electrode F suggests that copper plated first in the carbon felt layer near the current collector, and once electrical contact was established through the Daramic, copper then deposited into the carbon felt layer closest to the membrane. The dark areas observed in the carbon felts in Figure 10 are spaces where copper was not deposited. Uneven distribution of the copper plate across the surface is most likely due to variability in electrolyte wetting of the carbon felts. Copper deposit in both pieces of carbon felt in electrode $\mathrm{F}$ and the absence of copper deposit in the nonconducting felt in electrode $\mathrm{E}$ implies that each carbon felt can contain a finite plating density. If a higher plating density is desired, another layer can be added to electrode F, however this will further reduce the voltaic efficiency of the cell. An approach along these lines has been employed for $\mathrm{Zn}$ batteries [24, 25]. The balance of power delivered and energy capacity in a hybrid flow battery are coupled, and must be tailored to the specific application. It should also be noted that these results were obtained for plating at a single current density $\left(40 \mathrm{~mA} \mathrm{~cm}{ }^{-2}\right)$. It is likely that the maximum plating density that can be achieved within a porous electrode will be a function of the current density. A more rigorous investigation into the maximum plating density, as a function of the applied current, is required to fully characterize the electrode behavior [26]. 


\subsection{All-Iron Hybrid Flow Batteries}

Electrode designs $\mathrm{E}$ (bonded carbon felt and non-conducting felt) and $\mathrm{F}$ (bonded carbon feltDaramic-carbon felt) both achieved a plating density of over $150 \mathrm{mAh} \mathrm{cm}^{-2}$ in the $\mathrm{Cu}-\mathrm{Fe}$ sulfate battery. These electrode designs were then tested in an all-iron flow battery. Each battery was charged to $150 \mathrm{mAh} \mathrm{cm}^{-2}$, at a current density of $40 \mathrm{~mA} \mathrm{~cm}^{-2}$ (Figure 11). The potential and $\mathrm{iR}$ corrected potential for both batteries also shown in Figure 11, the latter corrected from the high frequency resistance of the EIS (Figure 12). The cell with electrode design E charged at a higher potential than the cell with electrode $\mathrm{F}(1.51 \mathrm{~V}$ versus $1.4 \mathrm{~V}$ respectively, at the end of charge). The $100 \mathrm{mV}$ difference in overpotential is mostly explained by the differences in high frequency resistance: the cell with electrode $\mathrm{E}$ was $4.2 \Omega \mathrm{cm}^{2}$, while the cell with electrode $\mathrm{F}$ was $3.3 \Omega$ $\mathrm{cm}^{2}$. When the charging-time plot of each cell is corrected for IR, the two charging curves are initially quite close, however begin to diverge after about one hour of charging, with cell $\mathrm{F}$ having a lower iR-corrected charging voltage as compared to cell E. EIS for both electrodes indicate a significant mass transfer resistance and relatively small charge transfer resistance. The EIS measured mass transfer resistances are significant in these cells, though mass transfer impedances were not present in the $\mathrm{Cu}-\mathrm{Fe}$ sulfate cells with the same electrode configurations (Figure 9). Due to the cell design and high porosity of the carbon felts, it is likely that hydrogen bubbles are trapped in the electrode structures and hindering mass transfer. Because the EIS was measured at the end of the initial charge, when the density of plated iron is the highest, the area of electrolyte flow and diffusion of ions to the electrode surface are reduced, again increasing the mass transfer resistances. The current distribution in electrode $\mathrm{F}$ is clearly non-uniformly distributed, making quantitative analysis of the charge transfer impedance difficult. Electrode $\mathrm{E}$ 
also shows distributed behavior, and the mass transfer semicircle somewhat overlaps the charge transfer semicircle.

After being charged to $150 \mathrm{mAh} \mathrm{cm}^{-2}$, the cells were cycled at $\pm 40 \mathrm{~mA} \mathrm{~cm}^{-2}$ for 30 minutes discharge and 30 minutes charge. The first six cycles are shown in Figure 13a, iR-corrected, along with the voltaic efficiency of each cycle (Figure 13b). The iR correction was done to directly compare the performance of the two electrodes without the inherently larger iR of Electrode $\mathrm{E}$ (due to the presence of the non-conducting felt). In the first cycle, electrode F shows a higher average voltaic efficiency $(86.3 \%)$ than electrode E, but the voltaic efficiency declines on each subsequent cycle (to $66.8 \%$ by cycle 6 ). Electrode E started at a slightly lower voltaic efficiency $(81.6 \%)$, but only decreased by $1.6 \%$ over six cycles. Coulombic efficiency is not considered here as each cycle was performed over a shallow depth of discharge, and coulombic losses caused by hydrogen evolution could not be estimated. A full investigation of the hydrogen evolution in the all-iron flow battery is beyond the scope of this paper and will be presented in a separate paper [27].

The two separate carbon felts in electrode $\mathrm{F}$, and thus two separate iron plates, may contribute to the decline in voltaic efficiency of electrode F. Plating in the layer closest to the membrane relies on electrical contact through the Daramic between the two carbon felt. Once that contact is made, the plating and stripping occurs in the carbon felt next to the membrane. Ion transport to the plated iron along the membrane is difficult, as is suggested by the large mass transfer resistance in the EIS results of electrode F (Figure 12). As the metal in electrode E was shown to deposit into the carbon felt instead of the non-conducting felt, electrolyte flow can more easily 
support ion transport through the porous media, lowering the mass transfer resistance. Electrode E can be further optimized by using a thinner non-conducting felt to minimize the cell resistance and by tailoring the current density to maximize plating density, though there will be an inherent limit to the amount of metal that can be plated in a single piece of carbon felt. The stability of electrode E throughout the cycling suggests it is better suited as a negative electrode than electrode F, even though electrode $\mathrm{F}$ had the lower cell resistance.

\section{Conclusions}

Traditional flow battery electrode configurations are difficult to use for negative electrode electrodeposition reactions, as non-uniform current distribution will deposit metal along the membrane-electrode interface, eventually blocking ion transport to the active surface Nonelectrically conductive porous materials were explored as components of a negative electrode structure to shift the current distribution away from the cell membrane and facilitate achieving a higher plating density. Bonding the porous electrode materials to the graphite flow field using a conductive ink reduced the interfacial resistance for both conductive and non-conductive porous materials. Plating results using a $\mathrm{Cu}-\mathrm{Fe}$ sulfate chemistry indicate a maximum plating density in a bonded carbon felt electrode without a non-conductive region of $145 \mathrm{mAh} \mathrm{cm}^{-2}$ before cell failure. Adding non-conducting porous materials to the negative electrode configuration increased the achievable plating density. Two negative electrode structures achieved at least 150 $\mathrm{mAh} \mathrm{cm}^{-2}$ in the $\mathrm{Cu}-\mathrm{Fe}$ sulfate chemistries: the bonded carbon felt and non-conducting felt, and the bonded carbon felt-Daramic-carbon felt electrodes. Electrochemical impedance spectroscopy 
showed little to no mass transfer resistance in the $\mathrm{Cu}-\mathrm{Fe}$ sulfate cells, indicating that mass transfer does not play a large role in flow battery operation.

In the all-iron chemistry, the negative electrode with a bonded carbon felt and a porous nonconducting felt maintained a voltaic efficiency of $81 \%$ over at least six cycles. The cell resistance in this battery was larger than in the battery with the bonded carbon felt-Daramiccarbon felt negative electrode. To reach a higher energy capacity, more layers of felt and the non-conducting materials can be added, however this will increase the cell resistance, reducing the power and energy storage capability of the battery. Tailoring the energy capacity versus the power towards each specific application of the battery will be necessary.

\section{Acknowledgements}

This work was funded through the U.S. Department of Energy, Office of Electricity Award \# $1111358,0$.

\section{References}

[1] EPRI, in, Electric Power Research Institute, Palo Alto, 2007.

[2] M. Skyllas-Kazacos, M.H. Chakrabarti, S.A. Hajimolana, F.S. Mjalli, M. Saleem, Journal of the Electrochemical Society, 158 (2011) R55-R79.

[3] C.P. de Leon, A. Frias-Ferrer, J. Gonzalez-Garcia, D.A. Szanto, F.C. Walsh, Journal of Power Sources, 160 (2006) 716-732.

[4] C.D. Wu, D.A. Scherson, E.J. Calvo, E.B. Yeager, M.A. Reid, Journal of the Electrochemical Society, 133 (1986) 2109-2112. 
[5] P.S. Fedkiw, R.W. Watts, Journal of the Electrochemical Society, 131 (1984) 701-709.

[6] L.W. Hruska, R.F. Savinell, Journal of the Electrochemical Society, 128 (1981) 18-25.

[7] A.Z. Weber, M.M. Mench, J.P. Meyers, P.N. Ross, J.T. Gostick, Q.H. Liu, Journal of Applied Electrochemistry, 41 (2011) 1137-1164.

[8] J. Jorne, J.T. Kim, D. Kralik, Journal of Applied Electrochemistry, 9 (1979) 573-579.

[9] R. Zito, US Patent US3719526 A (1973).

[10] H.S. Lim, A.M. Lackner, R.C. Knechtli, Journal of the Electrochemical Society, 124 (1977) $1154-1157$.

[11] P.K. Leung, C. Ponce-de-Leon, C.T.J. Low, A.A. Shah, F.C. Walsh, Journal of Power Sources, 196 (2011) 5174-5185.

[12] Y.H. Cheng, H.M. Zhang, Q.Z. Lai, X.F. Li, D.Q. Shi, L.Q. Zhang, Journal of Power Sources, 241 (2013) 196-202.

[13] R.G.A. Wills, J. Collins, D. Stratton-Campbell, C.T.J. Low, D. Pletcher, F.C. Walsh, Journal of Applied Electrochemistry, 40 (2010) 955-965.

[14] C.P. Zhang, S.M. Sharkh, X. Li, F.C. Walsh, C.N. Zhang, J.C. Jiang, Energy Conversion and Management, 52 (2011) 3391-3398.

[15] A.A. Shah, X. Li, R.G.A. Wills, F.C. Walsh, Journal of the Electrochemical Society, 157 (2010) A589-A599.

[16] T.G. Yan, L.H. Li, L.J. Wang, Bioresources, 8 (2013) 340-349.

[17] F. Mohammadi, P. Timbrell, S. Zhong, C. Padeste, M. Skyllaskazacos, Journal of Power Sources, 52 (1994) 61-68.

[18] Y. Mori, H. Yokoi, Bulletin of the Chemical Society of Japan, 67 (1994) 2724-2730. 
[19] Y.W.D. Chen, K.S.V. Santhanam, A.J. Bard, Journal of the Electrochemical Society, 128 (1981) 1460-1467.

[20] W.N. J. Euler, Electrochimica Acta, 2 (1960) 268-286.

[21] J.S. Newman, C.W. Tobias, J. Electrochem. Soc., 109 (1962) 1183-1191.

[22] J. Newman, W. Tiedemann, Aiche Journal, 21 (1975) 25-41.

[23] M.H. Chakrabarti, N.P. Brandon, S.A. Hajimolana, E. Tariq, V. Yufit, M.A. Hashim, M.A.

Hussain, C.T.J. Low, P.V. Aravind, Journal of Power Sources, 253 (2014) 150-166.

[24] C.A. Friesen, J.R. Hayes, R. Krishnan, T. Trimble, US Patent Application PCT/US2009/066823 (2010).

[25] C.A. Friesen, J.R. Hayes, US Patent Application PCT/US2009/040658 (2012).

[26] N.C. Hoyt, K.L. Hawthorne, J.S. Wainright, R.F. Savinell, Manuscript in Preparation.

[27] K.L. Hawthorne, T.J. Petek, M.A. Miller, J.S. Wainright, R.F. Savinell, Manuscript in Preparation 


\section{Figure Captions}

Figure 1. Bonded non-conducting felt rotating rod electrode. The active area of the copper rod is defined using Kapton tape, and the non-conducting felt is bonded to the active area using the conductive carbon ink.

Figure 2. Electrode structures tested in the $\mathrm{Cu}-\mathrm{Fe}$ sulfate battery. Structures A-C were also tested in symmetric cells, with a separate naming convention (the third structure tested in symmetric cells, non-bonded non-conducting felt, is not shown). Structures E and F were also tested in all-Fe batteries.

Figure 3. Calculated current distribution in a porous conductive electrode, at varying ratios of electronic conductivity to ionic conductivity. Parameters used in the calculation include: bulk $\mathrm{Fe}^{3+}$ concentration $=0.25 \mathrm{M}, \mathrm{Fe}^{3+}$ diffusion coefficient $=4.76 * 10-6 \mathrm{~cm} \mathrm{~s}^{-1}$, ionic conductivity $=$ $0.1 \mathrm{~S} \mathrm{~cm}^{-1}$, exchange current density $=1.5 \mathrm{~mA} \mathrm{~cm}^{-2}$, anodic alpha $=0.4$, cathodic alpha $=0.6$, local limiting current density $=100 \mathrm{~mA} \mathrm{~cm}$, void fraction $=0.8$, felt roughness factor $=360 \mathrm{~cm}^{2}$ $\mathrm{cm}^{-3}$, temperature $=298 \mathrm{~K}$.

Figure 4 . Initial charge of the flow-by copper sulfate battery at $40 \mathrm{~mA} \mathrm{~cm}{ }^{-2}$. Membrane area was $5 \mathrm{~cm}^{2}$, with serpentine flow fields and carbon paper electrodes (described in the Flow-By Battery methodology section).

Figure 5. Plated copper in the flow-by copper sulfate battery, using $5 \mathrm{~cm}^{2}$ serpentine hardware (deposition rate of $40 \mathrm{~mA} \mathrm{~cm}^{-2}$, with a total deposit of $73 \mathrm{mAh} \mathrm{cm}^{-2}$ ) at a) the membrane face of 
the carbon paper, showing uniform copper deposit and b) the current collector face of the carbon paper, showing essentially no copper deposit in the paper. Copper is observed around the edges of the paper in both pictures, most likely due to the high overpotential and mass transfer resistances near the end of the cell life.

Figure 6. Nyquist plots around OCV for symmetrically run flow cell with A: bonded carbon felt, B: non-bonded carbon felt, C: bonded non-conducting felt, and D: non-bonded non-conducting felt electrode configurations. Electrolyte was $0.2 \mathrm{M} \mathrm{FeCl}_{2}, 0.2 \mathrm{M} \mathrm{FeCl}_{3}$, and $1 \mathrm{M} \mathrm{NaCl}$.

Figure 7. Cyclic voltammetry of iron deposition and stripping on a bonded non-conducting felt rotating rod after 0,20 , and $480 \mathrm{mAh} \mathrm{cm}^{-2}$, and compared to a cyclic voltammogram on a copper rod. Electrolyte was $0.2 \mathrm{M} \mathrm{FeCl}_{2}$ and $1 \mathrm{M} \mathrm{NH}_{4} \mathrm{Cl}$.

Figure 8. Charging potential-time curves for electrodes A (bonded carbon felt), B (non-bonded carbon felt), C (Bonded non-conducting felt), D (Bonded carbon cloth and non-conducting felt), E (bonded carbon felt and non-conducting spacer), and F (bonded carbon felt-Daramic-carbon felt) in a $\mathrm{Cu}-\mathrm{Fe}$ sulfate battery. Charged at $40 \mathrm{~mA} \mathrm{~cm}^{-2}$ for 230 minutes, or until the voltage sharply increased, indicating failure.

Figure 9. Nyquist plots around OCV for negative electrodes C (bonded non-conducting felt), D (bonded carbon cloth and non-conducting felt), E (bonded carbon felt and non-conducting felt), and $\mathrm{F}$ (bonded carbon felt-Daramic-carbon felt) in the $\mathrm{Cu}-\mathrm{Fe}$ sulfate batteries after charge. EIS 
for electrodes A and B was unable to be determined. Each spectrum is offset by $0.1 \mathrm{ohm}$ in Z" for clarity.

Figure 10. $150 \mathrm{mAh} \mathrm{cm}^{-2}$ of plated copper in a) electrode $\mathrm{E}, \mathrm{b}$ ) the carbon felt nearest to the current collector in electrode F, and c) the carbon felt nearest to the membrane in electrode F. Dark areas are exposed carbon felt, where copper did not deposit.

Figure 11. Initial charge of all-iron hybrid flow batteries with the bonded felt and nonconducting felt negative electrode (electrode E) and the bonded felt-Daramic-felt (electrode F) negative electrode. IR free curves were calculated using high frequency resistances from EIS.

Figure 12. Nyquist plots of the all-iron hybrid flow batteries around the open circuit potential with electrode E (bonded felt and non-conducting felt) and electrode F (bonded carbon feltDaramic-carbon felt) negative electrodes.

Figure 13. a) IR corrected potential during cycling of all-iron batteries with electrodes $E$ (bonded carbon felt and non-conducting spacer) and F (bonded carbon felt-Daramic-carbon felt) at $\pm 40 \mathrm{~mA} \mathrm{~cm}{ }^{-2}$, and b) average voltaic efficiency per cycle number for the iR corrected cycles with electrode $\mathrm{E}$ and electrode $\mathrm{F}$. 


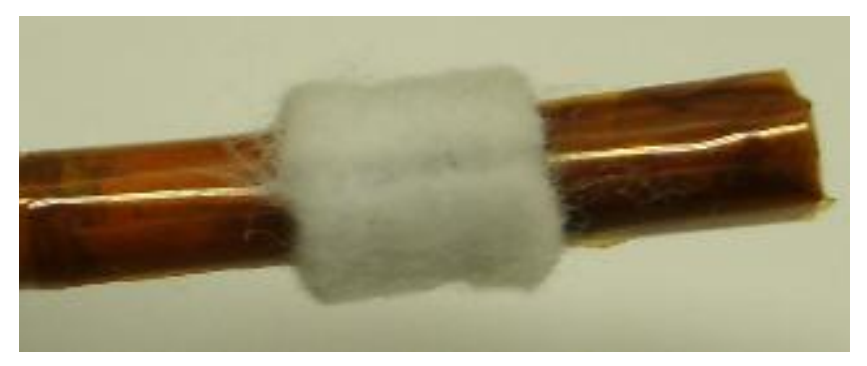



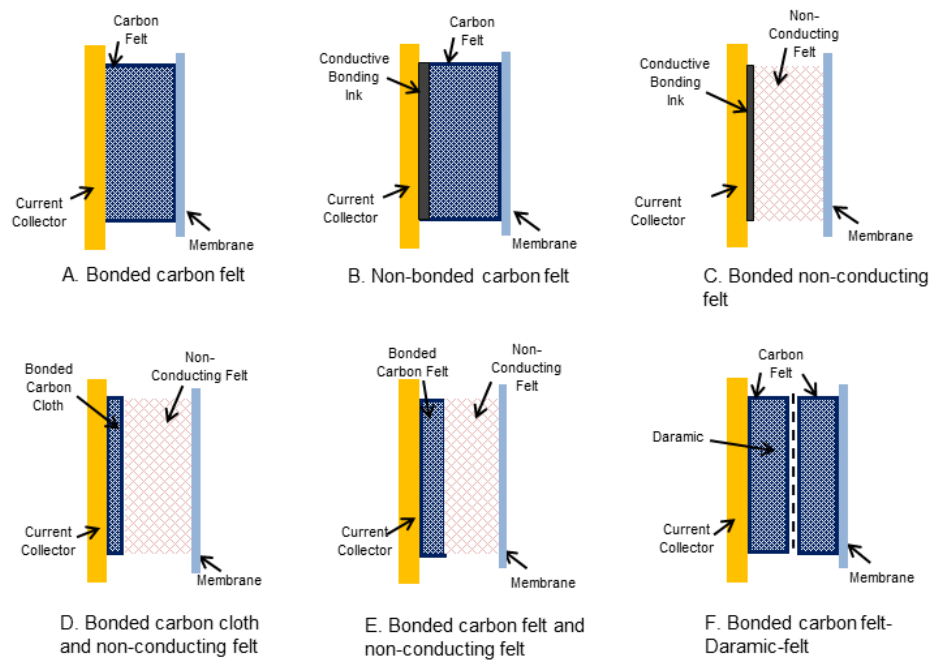


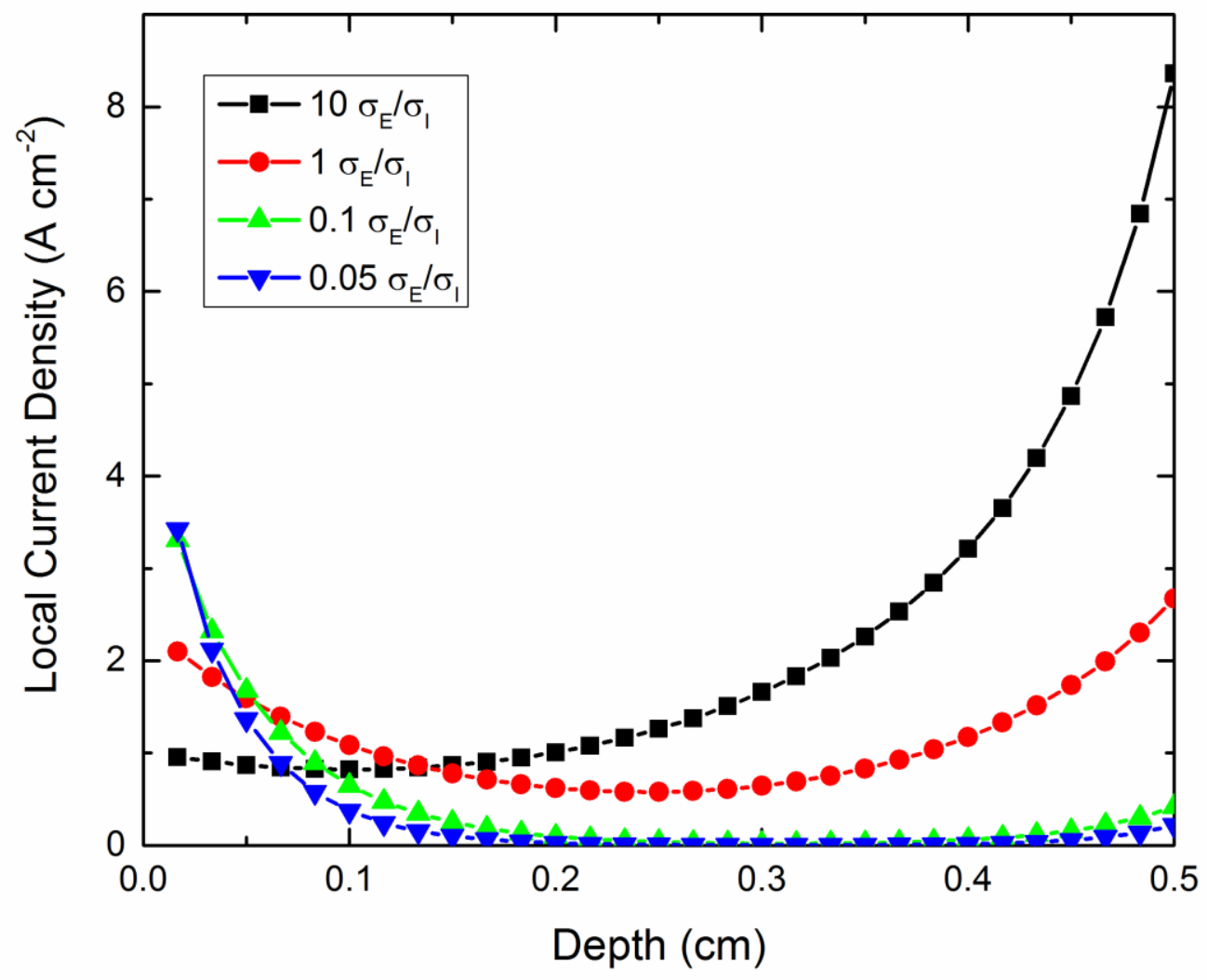




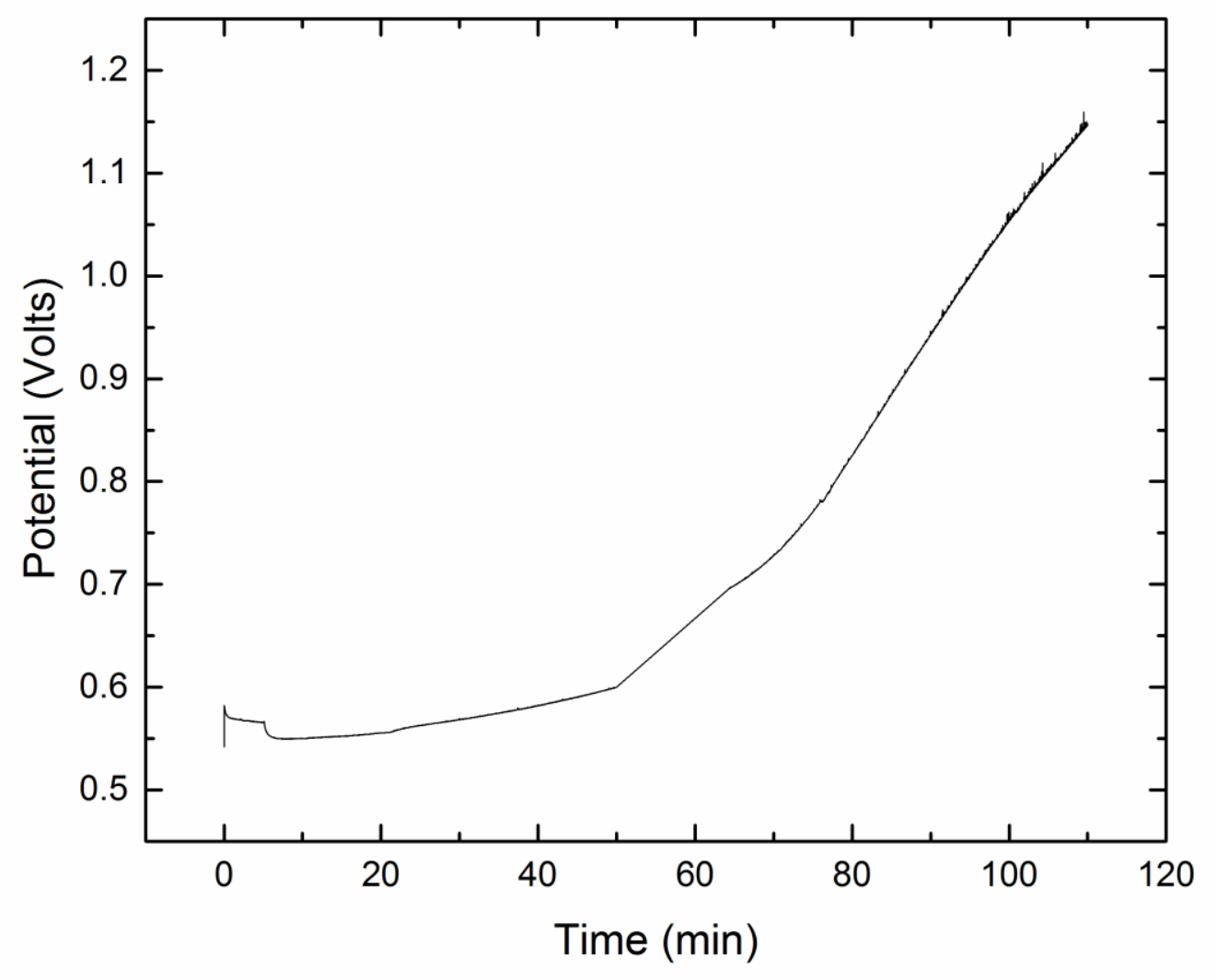




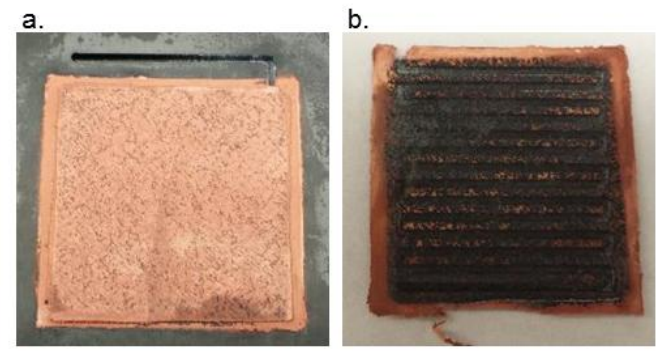




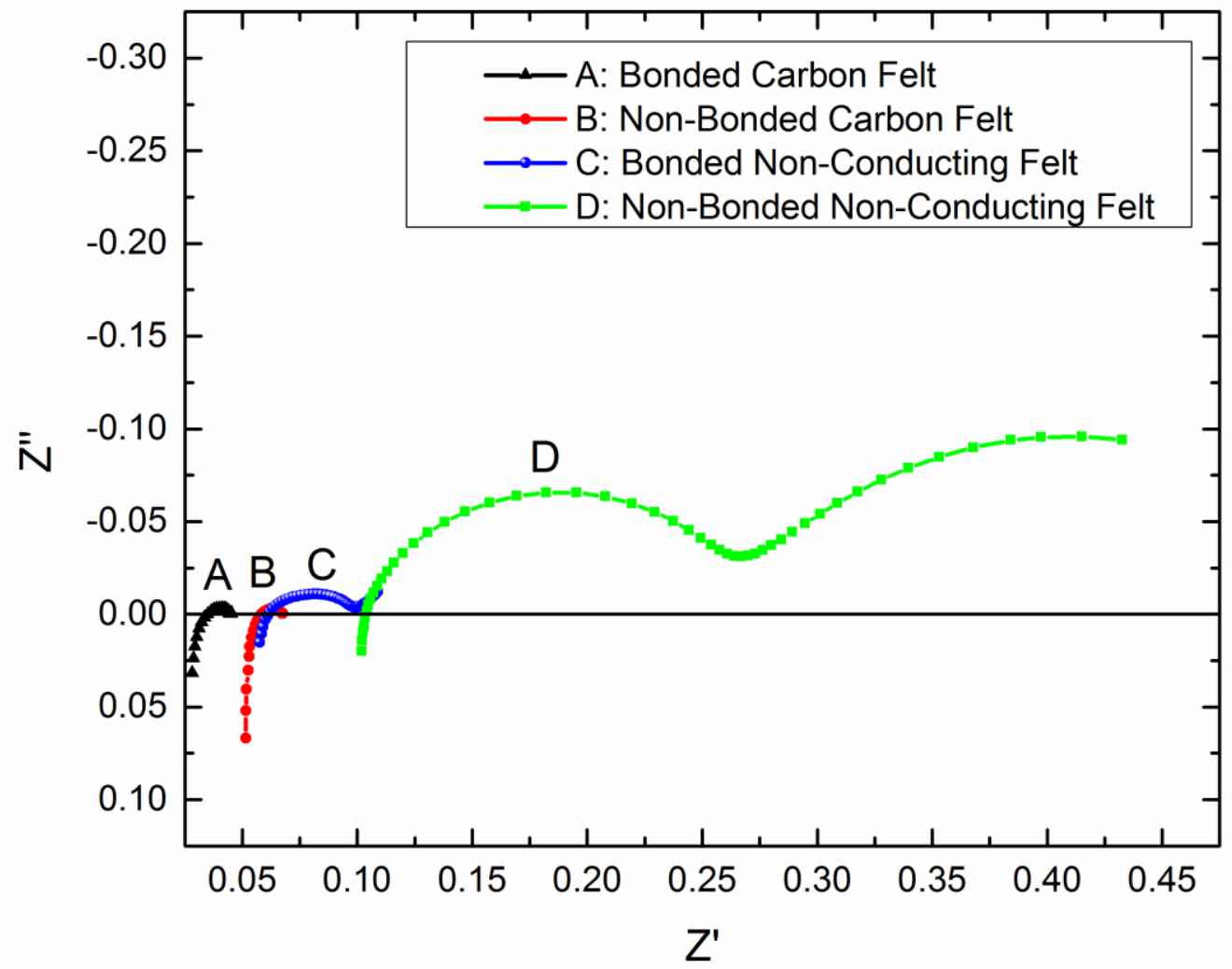




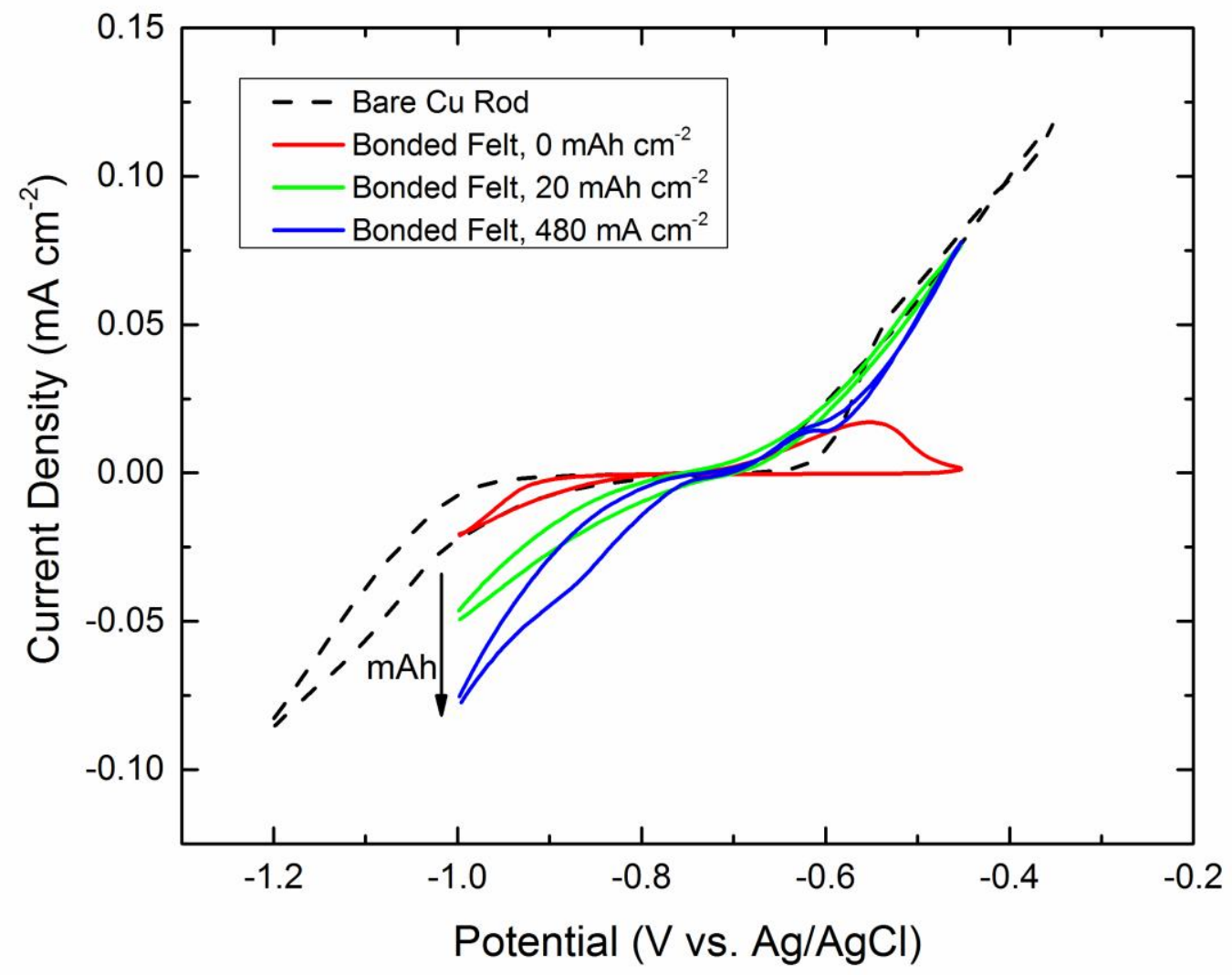




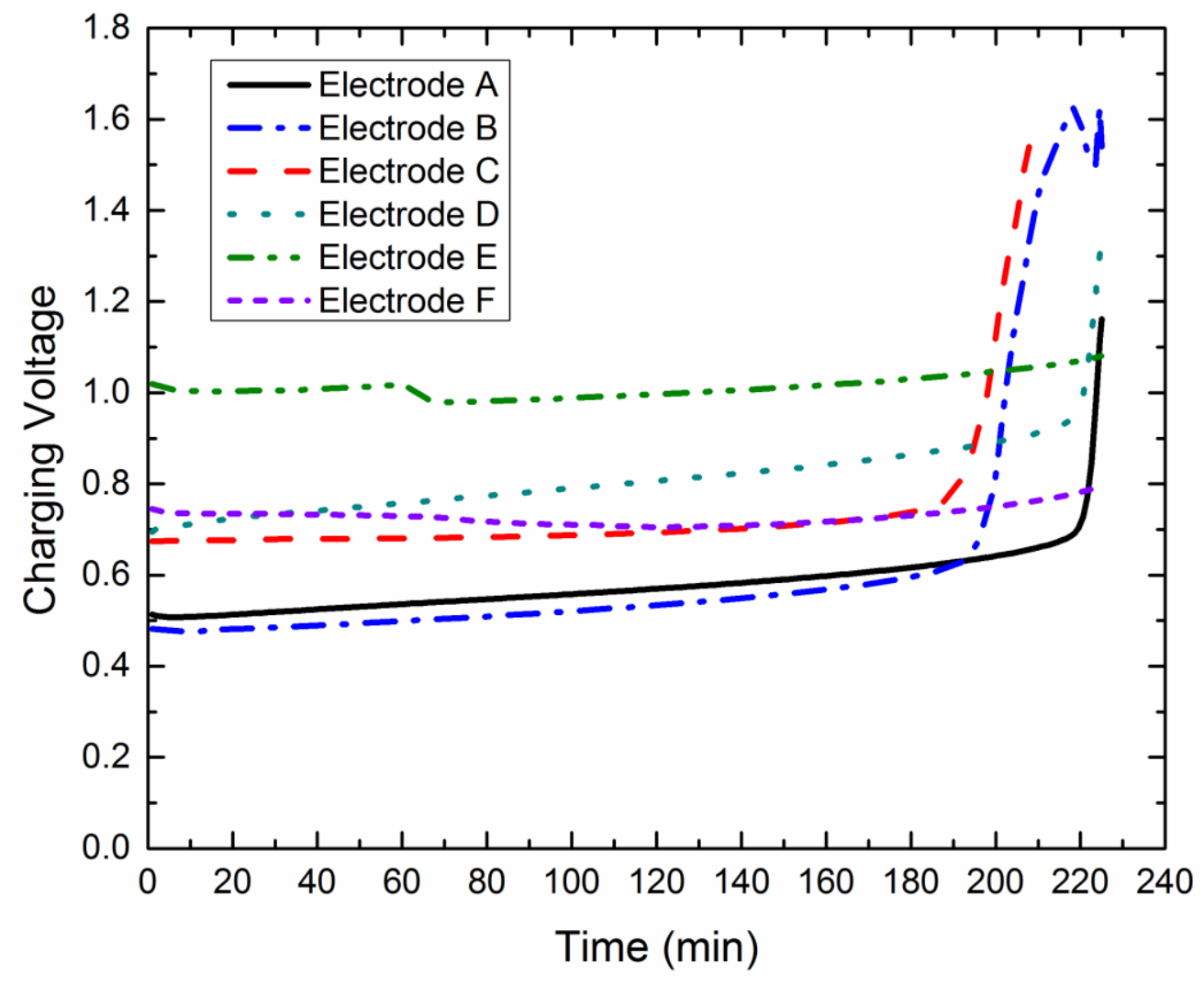




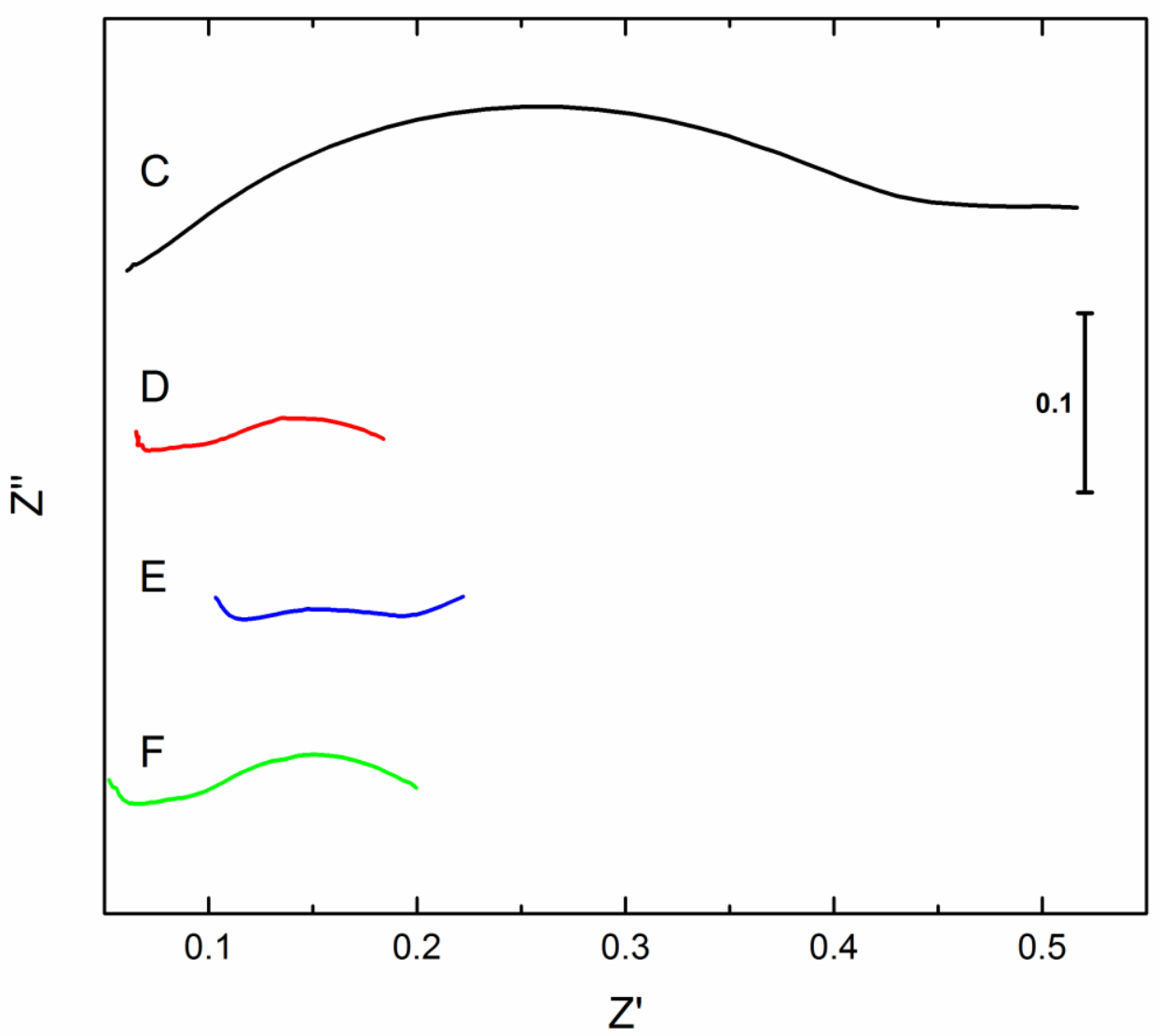




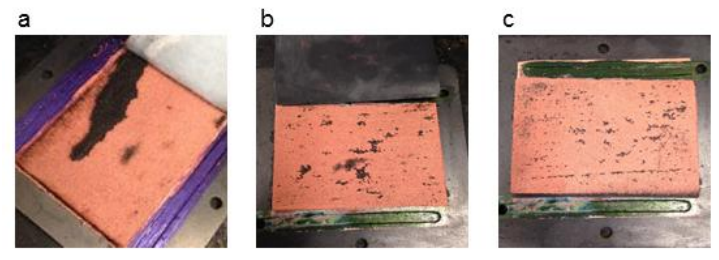




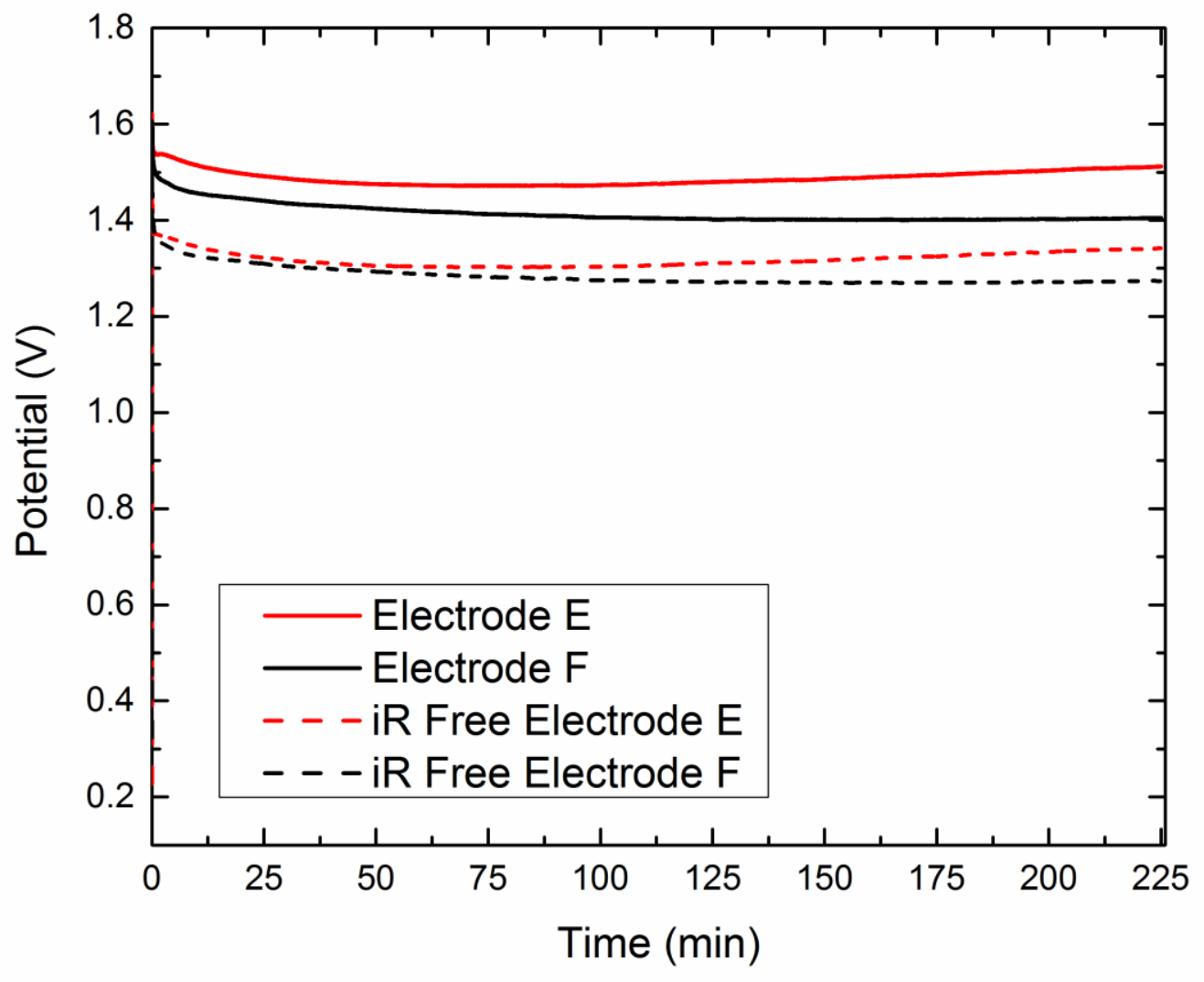




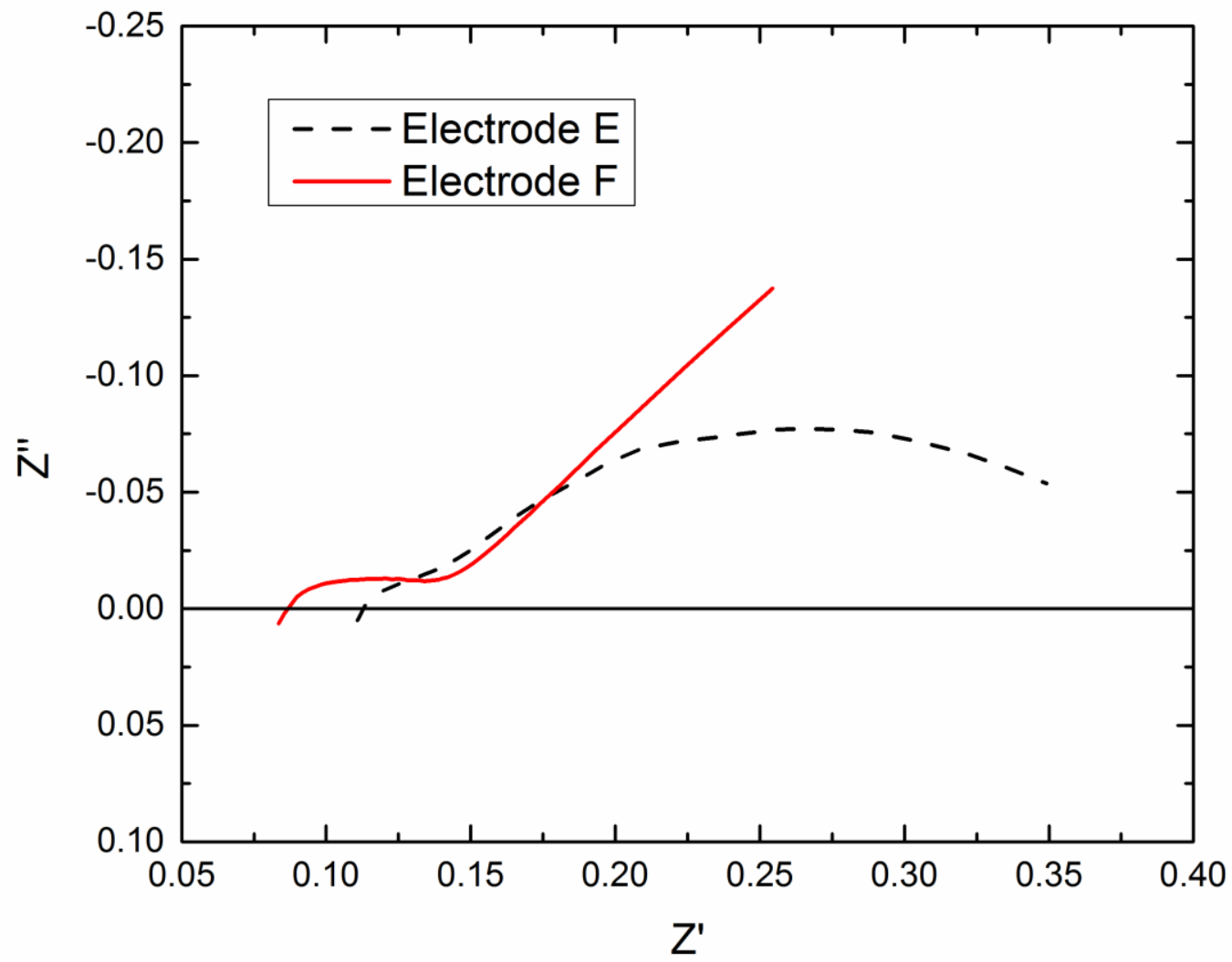



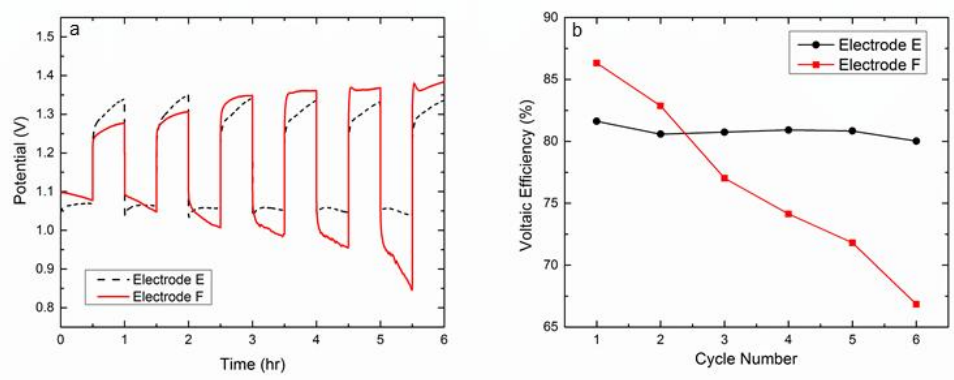
Table 1. Summary of Cu-Fe Batteries

\begin{tabular}{lccc}
\hline Structure & $\begin{array}{c}\mathbf{R}_{\mathbf{H F}} \\
\left(\mathbf{\Omega} \mathbf{~ c m}^{2}\right)^{\mathbf{a}}\end{array}$ & $\begin{array}{c}\text { Charging } \\
\text { Potential }(\mathbf{V})\end{array}$ & $\begin{array}{c}\text { Plating Density } \\
\left(\mathbf{m A h} \mathbf{~ c m}^{-2}\right)\end{array}$ \\
\hline A. Bonded carbon felt & N.D. & 0.66 & 145 \\
B. Non-bonded carbon felt & N.D. & 0.62 & 128 \\
C. Bonded non-conducting felt & 3.85 & 0.75 & 124 \\
D. Bonded carbon cloth and non-conducting felt & 2.31 & 0.93 & 145 \\
E. Bonded carbon felt and non-conducting felt & 3.08 & 1.08 & $150+^{c}$ \\
F. Bonded carbon felt-Daramic-carbon felt & 1.93 & 0.79 & $150+^{c}$ \\
\hline
\end{tabular}

\footnotetext{
${ }^{a} \mathrm{R}_{\mathrm{HF}}$ calculated from the high frequency intercept from the EIS in Figure 9

${ }^{\mathrm{b}}$ Charging potential refers to the potential measured near the end of the charging curves, either just before cell failure began or at 230 minutes (if failure did not occur)

${ }^{\mathrm{c}}$ Electrode did not reach full plating capacity (experiments stopped at $150 \mathrm{mAh} \mathrm{cm}^{-2}$ )
} 